\title{
Tax Competition and Foreign Capital
}

By Ronald B. Davies, University of Oregon

and Thomas A. Gresik, University of Notre Dame*

$\begin{array}{ll}\text { Send correspondence to: } & \text { Professor Thomas A. Gresik } \\ \text { Mendoza College of Business } \\ \text { University of Notre Dame } \\ \text { Notre Dame, IN 46530 } \\ \\ \text { 574-631-9341 } \\ \text { tgresik@nd.edu }\end{array}$

\begin{abstract}
This paper derives welfare equivalence of double taxation rules in a tax competition model with discriminatory home taxes and the ability to finance subsidiary operations with host country capital. For a more general model, we provide sufficient conditions on the number of host sectors and factors that support double-tax-rule equivalence. Examples violating these conditions help identify economic factors under which a home country's has strict preferences over double taxation rules. If the home tax rate can influence host factor prices, the home country weakly prefers deductions over credits as in the pure-homeequity financing case.
\end{abstract}

Keywords: tax competition, double taxation, foreign capital 
Multinationals rely on a variety of sources to finance subsidiary operations: parent equity, parent debt, retained earnings, host equity, and subsidiary debt. While the degree to which a multinational utilizes its available sources depends in part on marginal tax effects, extant models of tax competition have assumed that multinationals rely exclusively on parent equity. Our goal in this paper is to begin to develop a theory of tax competition for multinational investment that accounts for multiple financing sources. We do this by adding foreign capital, either debt or equity, as a financing option and examine how it influences tax competition in a general equilibrium setting.

As Horst (1977) first noted, a significant proportion of subsidiary financing comes from retained earnings and foreign debt, that is, borrowing outside the parent corporation's home country. Table 1 (summarizing evidence from Feldstein (1995)) shows that in 1989 foreign debt accounted for $46 \%$ of the $\$ 1,237$ billion of (non-bank) foreign direct investment. ${ }^{1}$ Parent equity (broadly defined as equity plus retained earnings) accounted for a similar percentage of FDI. Given the dominant share of FDI financed by home equity and foreign capital, we focus on the interplay between these two financing sources.

[TABLE 1 HERE]

Despite the apparent importance of foreign debt as a financing source and the sensitivity of corporate finance to tax policy, the role of foreign capital in strategic models of tax competition has yet to be considered. ${ }^{2}$ With several sources of financing, tax rate changes can not only affect where home country capital is invested, it can also affect the distribution of host country capital and labor between host industries and foreign subsidiaries. The relationship between taxes and host debt has been demonstrated theoretically by Newlon (1987), who introduced subsidiary debt into a dynamic model of multinational financing, and by Leechor and Mintz (1993) and Hines (1994), who explain how a subsidiary's debt-equity ratio can be sensitive to both domestic and host tax rates. Empirically, Horst (1977) found that accounting for subsidiary debt significantly altered the estimated effects of several investment tax policies. More recently, Altshuler and Mintz (1995) show that certain provisions in the 
Tax Reform Act of 1986 (TRA 1986) created a bias against direct borrowing by parent firms to finance subsidiary investment and increased the proportion of foreign to domestic debt. ${ }^{3}$

To formally examine how host capital influences investor and government behavior, we analyze a game in which a home (capital exporting) and a host (capital importing) government simultaneously set tax rates on subsidiary profit to maximize their respective national incomes, after which multinational investors and local host investors make capital allocation, host financing, and employment decisions. Home capital owners must allocate their capital between domestic production and subsidiary production located in the host country. In addition to equity capital, subsidiary production can make use of host capital.

Our results reveal that the availability of host financing substantially changes a home government's incentives to tax overseas profits. When the effective tax on home equity invested in the host country changes, this leads to movements in host factors from one sector to another. This linkage between taxes and host factor allocations can be understood in terms of the Rybczynski (1955) effect from trade theory which shows that when the supply of a factor increases, output increases in the sector that uses that factor more intensively. Since an increase in the effective tax reduces equity FDI, this is akin to a reduction in the host capital stock and leads to a reallocation of factors. Furthermore, as in the original formulation of the Rybczynski effect, under constant returns to scale this reallocation occurs without changing host factor prices.

Because home and host taxes together define an effective tax rate, this reallocation is important for optimal tax policies. For the host country, its trade-offs are straightforward: a higher host rate versus a lower capital base. Home country trade-offs are more complicated. Since all home (and host) investors are assumed to be small relative to both home and host markets, they make investments taking factor prices as given. However, in the aggregate, an increase in host factors used in subsidiary production can raise host factor prices. This presents the home government with a higher marginal cost for host factors 
than individual home investors and implies excessive host-capital financing and excessive host employment by home subsidiaries from the home government's perspective.

In order to determine how host financing changes home's optimal tax strategy and hence equilibrium tax rates, it is necessary to translate statutory home and host tax rates into an effective tax rate on home capital. Since subsidiary profits (net of host labor and, in the case of foreign debt, lending costs) are subject to taxation by both countries; first by the host country and then upon repatriation by the parent's home country; the possibility of double taxation exists. Most capital-exporting countries either exempt foreign source earnings from home taxation or provide a credit, up to the home liability, for host taxes. A limited number of countries require a deduction for foreign taxes or provide no double taxation relief. We derive the set of subgame perfect Nash equilibria of our tax competition game for all three relief methods and compare them to the equilibria that arise when only home-equity financing is considered.

For any fixed set of tax rates and only home-equity financing, Hamada (1966) showed that a credit rule encourages more outbound capital flows than deductions by yielding a lower effective tax rate. Bond and Samuelson (1989) proved that this very same feature encourages both governments to set higher tax rates with credits. In all Nash equilibria of their tax competition game in which the home government uses a credit method, this more aggressive taxation eliminates all capital flows. This result is due to two effects. First, once home's tax rate exceeds a certain level, the host country always wishes to match home's rate. Under credits this allows the host country to capture all of the tax revenue generated by the FDI without distorting the factor markets. Second, by setting its tax rate above the host rate, the home country can induce a "terms-of-trade" effect, that is, it can influence host factor prices such that national income losses due to lower outbound capital flows are offset by higher returns on investment abroad. In our baseline model, although the home government still desires to affect host factor prices, the introduction of host financing makes the host factor prices unresponsive to changes in the home rate. 
This implies welfare-equivalent, positive capital flow equilibria under all three methods.

This equivalence among relief methods is similar to Janeba's (1995) result. A key difference is that whereas Janeba assumes non-discriminatory home tax rates, we analyze the discriminatory case studied by Bond and Samuelson (1989) in which the home government can tax domestic-source and foreign-source income at different rates. ${ }^{4}$ Studies by Hines (1988) and Wilson (1993) show that typical home tax policies such as accelerated depreciation for domestic investments effectively result in discriminatory tax rates and suggest that Janeba's results may not adequately reflect the impact of home taxes on multinational investment. Thus, a key implication of our model is that it is possible to recover the Janeba-type equivalence even with discriminatory taxation.

We proceed as follows. In Section 1, we present our baseline model and show that a Janeba-type equivalence can arise even under discriminatory taxation. We then generalize our model in Section 2 and present sufficient conditions on the number of host sectors and factors that preserves our equivalence result. In Section 3, we present two modifications to the baseline model that recover the Bond and Samuelson equilibria and imply strict home preferences between a deduction and credit rule. Independent of tax competition issues, our model also generates implications for subsidiary leverage as a function of the effective tax rate on subsidiary profits and the relative capital intensity of the subsidiary sector to the domestic host sector. We explore this relationship in Section 4. Extensions and concluding remarks are in Section 5.

\section{The Base Model.}

In this section, we develop a model with two national income maximizing countries: home and host. A representative investor in each country is endowed with an inelastic supply of capital and labor, which are used to produce a single homogenous good of unitary price. Both the factor and goods markets are assumed to be perfectly competitive. Home and host capital-labor endowments are $(K, L)$ and $\left(K^{*}, L^{*}\right)$. Home production is described by $F$ while two production processes are present in the host country: host- 
owned production (denoted by $F^{*}$ ) and production using a transferred technology from the home country, also known as subsidiary production (denoted by $\left.F^{s}\right){ }^{5}$ All three production functions exhibit constant returns to scale and are strictly concave. The three technologies are allowed to differ, and it is assumed that neither subsidiary nor host production is eliminated in equilibrium. ${ }^{6}$

Subsidiary production embodies three items of note. First, it represents a technology transfer to the host country. Second, labor is assumed to be internationally immobile implying that all subsidiary labor $\left(L^{s}\right)$ must come from the host country. Third, a subsidiary's capital needs can be satisfied through direct foreign investment (denoted by $Z$ in the aggregate) as well as an ability to obtain additional capital (denoted by $K^{s}$ in the aggregate) from host firms. ${ }^{7}$ In our base model, $Z$ and $K^{s}$ are perfect substitutes. Consistent with the empirical findings of Feldstein and Horioka (1980), we assume capital market imperfections that effectively segment the home and host capital markets. This allows for the possibility that multinational investment serves as a channel through which after-tax returns on home and host capital can be equalized. We also assume that, in the absence of tax effects, the equilibrium value of $Z$ will be positive. ${ }^{8}$ Finally, we retain several assumptions common in extant tax competition models: static production and no transfer pricing. A static model rules out the use of retained earnings which are used by mature subsidiaries (see Hartman (1985)) to finance new investments and it rules out the ability to carry back or carry forward excess foreign tax credits. Both possibilities introduce a number of dynamic issues that are presently beyond the scope of this paper as well as existing tax competition models.

The home capital owner seeks to maximize her after-tax returns through the choice of exported capital, host capital, and home and host labor taking the cost of home labor $(w)$, host labor $\left(w^{*}\right)$, and host $\operatorname{debt}\left(r^{*}\right)$ as given. The host government taxes subsidiary returns, net of the cost of host labor and borrowed host capital, at a rate $t^{*}$. The home government assesses a tax liability on subsidiary returns, net of the same costs, at a rate $t$. Depending on which double taxation method is adopted, this home tax liability can be reduced yielding an effective total tax rate on subsidiary returns of $t^{e}$. For the three basic 
types of double taxation rules, ${ }^{9}$

$$
t^{e 1}\left\{\begin{aligned}
t^{1} & \text { if home offers an exemption } \\
t \% d^{\prime} \& t t^{(} & \text {if home offers a deduction } \\
\max \left\{t, t^{\prime}\right\} & \text { if home offers a credit. }
\end{aligned}\right.
$$

\subsection{Factor Market Equilibria.}

At the aggregate level, consider the situation in which the home capital owner invests $Z$ units of home capital and $K^{s}$ units of borrowed host capital in her subsidiary. ${ }^{10}$ This capital investment is combined with $L^{s}$ units of host labor. Due to the one-period nature of this model, all after-host-tax subsidiary profits are assumed to be repatriated to the parent. This gives aggregate global post-tax profits of

$$
\pi^{\prime} F(K \& Z, L) \& w L \%\left(1 \& t^{e}\right)\left[F^{s}\left(Z \% K^{s}, L^{s}\right) \& r^{(} K^{s} \& w^{(} L^{s}\right]
$$

For the host investor, aggregate profits from local production and lending are

$$
\pi^{(}{ }^{\prime} F^{(}\left(K^{(} \& K^{s}, L^{(} \& L^{s}\right) \& w^{(}\left(L^{(} \& L^{s}\right) \% r^{\prime} K^{s} \cdot{ }^{11}
$$

Factor market equilibria will satisfy

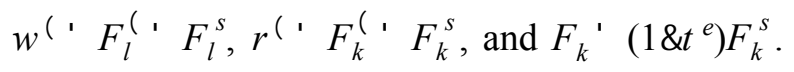

Totally differentiating (3) shows that

$$
\begin{aligned}
& \frac{d Z}{d t^{e}}, \frac{F_{k}}{\left(1 \& t^{e}\right) F_{k k}}<0, \\
& \frac{d K^{s}}{d t^{e}}, \frac{\& F_{k} k^{(}}{\left(1 \& t^{e}\right) F_{k k}\left[k^{(} \& k^{s}\right]}<0 \text { if } k^{s}>k^{\prime}, \text { and } \\
& \frac{d L^{s}}{d t^{e}}, \frac{\& F_{k}}{\left(1 \& t^{e}\right) F_{k k}\left[k^{(} \& k^{s}\right]}<0 \text { if } k^{s}>k^{(}
\end{aligned}
$$

where $k^{s}=\left(Z+K^{s}\right) / L^{s}$ and $k^{*}=\left(K^{*}-K^{s}\right) /\left(L^{*}-L^{s}\right)$ are the capital-labor ratios employed in subsidiary and host production. ${ }^{12}$ 
There are three items worthy of note here. First, by concavity of the production functions, $d Z / d t^{e}$ is negative, while movements in $K^{s}$ and $L^{s}$ due to tax changes are ambiguous. This ambiguity is related to the Rybczynski effect (1955), whereby an increase in the supply of a factor increases output in the sector using that factor intensively, and in this two sector case, decreases output in the other sector. When $t^{e}$ rises, $Z$ decreases, reducing the total supply of capital in the host country. Because the change in $t^{e}$ does not directly affect host- or subsidiary-sector marginal products, any change in $K^{s}$ and $L^{s}$ is due solely to the change in $Z$. This fact allows us to apply a Rybczynski interpretation to our factor market comparative statics. Thus, if the subsidiary "sector" is more capital intensive than the host sector, the drop in $Z$ decreases subsidiary production and hence induces decreases in host financing and subsidiary labor. Conversely, if host production is capital intensive, host production falls while subsidiary output rises. Now an increase in $t^{e}$ decreases $Z$ and increases $K^{s}$ and $L^{s}$. Second, $d k^{s} / d t^{e}=d k^{*} / d t^{e}=0$. Because production exhibits constant returns to scale, changes in $t^{e}$ will not affect equilibrium capital-labor ratios for either host or subsidiary production even though the levels of FDI, host financing, and subsidiary labor will change. As a result, host and subsidiary capital-labor intensities are independent of the home production technology and tax rates. Under constant returns to scale, this also implies that host factor prices are independent of taxes. Finally, since $Z$ is always decreasing in $t^{e}$, we can again define $t^{\max }$ to be the lowest effective tax rate such that $Z=0$.

\subsection{Government Preferences.}

The two governments simultaneously set their tax rates to maximize national income, anticipating how this will alter $Z, K^{s}$, and $L^{s}$. Because the production functions exhibit constant returns to scale, home national income or domestic production plus after-host-tax subsidiary profit for the case of host debt is

$$
Y\left(t, t^{(}\right)^{\prime} F \%\left(1 \& t^{(}\right)\left[F_{k}^{s}\left(K^{s} \% Z\right) \% F_{l}^{s} L^{s} \& r^{\prime} K^{s} \& w^{(} L^{s}\right]
$$

Using (3), this is equivalent to ${ }^{13}$

$$
Y^{\prime} F \% \frac{1 \& t^{\prime}}{1 \& t^{e}} F_{k} Z
$$


With any double taxation rule, the home rate, $t$, affects $Y$ only through $t^{e}$. Therefore, home's first order condition is

$$
\frac{M}{M}{ }^{\prime} \frac{M}{M^{e}} \frac{M^{e}}{M}{ }^{\prime}\left(\left[\frac{t^{e} \& t^{\prime}}{1 \& t^{e}} F_{k} \& \frac{1 \& t^{\prime}}{1 \& t^{e}} F_{k k} Z\right] \frac{M}{M^{e}} \% \frac{1 \& t^{\prime}}{\left(1 \& t^{e}\right)^{2}} F_{k} Z\right) \frac{M^{e}}{M} .
$$

The bracketed term is the difference between a volume effect and a terms of trade effect. The last term in parenthesis on the right-hand side of (7) is a direct tax revenue effect. As long as $M^{e} / M$ is not zero, we can focus on the behavior of $t^{e}\left(t^{*}\right)$, home's preferred effective tax as a function of the host tax.

How $Y$ varies with $t^{e}$ depends on the magnitude of the various effects in (7). Using (3) and (4),

(7) reduces to

$$
\frac{M}{M^{e}} \cdot \frac{\left(t^{e} \& t^{(}\right)}{\left(1 \& t^{e}\right)^{2}} \frac{F_{k}^{2}}{F_{k k}}
$$

This tells us that the positive tax effect is exactly offset by the terms of trade effect. With only a volume effect, home prefers not to distort capital flows and will set the effective tax equal to the host statutory tax. Thus, home national income is maximized when $t^{e}\left(t^{\prime}\right)^{\prime} t^{\prime}$.

Similar to the home country, host national income or host firm production plus subsidiary production net of repatriated profit equals

$$
Y^{(}\left(t, t^{\prime}\right)^{\prime} F^{(} \% F^{s} \& \frac{1 \& t^{\prime}}{1 \& t^{e}} F_{k} Z
$$

Given $t^{*}$, we assume that $Y$ is piecewise concave in $t$. Concavity can fail to hold with a credit rule at $t=t^{*}$. Similarly, we assume, given $t$, that $Y^{*}$ is piecewise concave in $t^{*}$ relative to the same boundaries. Note that the host is concerned with both the effective tax and its statutory tax. We will therefore describe host preference in more detail under each of the double tax rules.

\section{Welfare Equivalent Double Tax Rules.}

\subsection{Exemptions.}

Under exemptions, the home government has no strategic role since $\mathbf{M}^{e}\left(t, t^{(}\right) / \mathrm{M}^{\prime} 0$. As a result, the host government's problem simply involves choosing $t^{*}$ to maximize $Y^{*}\left(0, t^{*}\right)$. The solution to this

problem, denoted $t_{\text {opt }}^{(}$, admits the simple characterization $t_{\text {opt }}^{(} 1 /(1 \%)$ where $\varepsilon^{\prime} \& F_{k} / F_{k k} Z$ is the supply 
elasticity of exported home capital.

\subsection{Credits.}

If the home government offers a tax credit for host taxes, $t^{e}=\max \left\{t^{*}, t\right\}$. Notice that when $t>t^{*}, \quad M^{(} / M^{(}{ }^{\prime} F_{k}^{s} Z$ and that when $t \# t^{*}$, host's problem is identical to that under exemptions.

Therefore, host's best response to any home rate $t$ is $t_{c}^{(}(t){ }^{\prime} \max \left\{t, t_{\text {opt }}^{(}\right\}$.

\subsection{Deductions.}

Under deductions, $t^{e}=t+t^{*}-t t^{*}$ and the iso-effective tax lines are concave in $\left(t, t^{*}\right)$-space. Two characteristics of the host best response are key to our analysis. First, when $t=0$, the host will simply chose its optimal tax $t_{\text {opt }}^{(}$. Second, when $t^{\prime} t^{\max }$, capital flows are zero, implying that $t^{(}$' 0 is a (nonunique) best response. As a result, the host best response must be decreasing in the home tax over some range of home rates. While the exact value of $t_{d}^{(}(t)$, host's best-response under deductions, can be found by differentiating (9) with respect to $t^{*}$, for our purposes we need only recognize that it is never a best response to choose a tax that increases the effective tax rate above $t^{\max }$ unless $t$ already exceeds this level.

\subsection{Equilibrium Welfare Comparisons.}

We now combine this information on best responses for our main result.

Proposition 1: For the base model in which home and host capital are perfect substitutes, there exist equilibria under all three double-tax relief methods that are welfare equivalent to $\left\{t, t^{\prime}\right\}^{\prime}\left\{0, t_{\text {opt }}^{(}\right\}$. Proof: The home best response is to set, $t^{e}\left(t^{t}\right)^{\prime} t^{\prime}$. Under exemptions, this is automatic since the home tax is constrained to zero. Under deductions this implies $t=0$, regardless of $t^{*}$. Under credits, an effective tax equal to the host tax is achieved by setting $t \# t^{\prime}$. Combining this information with the host best response, this implies that the positive capital flow equilibria under exemptions and deductions are identical and given by $\left\{t, t^{\prime}\right\}^{\prime}\left\{0, t_{\text {opt }}^{(}\right\}$. For credits, there are a continuum of equilibria such that $t \# t^{(} \cdot t_{\text {opt }}^{(}$all of which yield the same effective tax rate $t_{\text {opt }}^{(}$. Therefore, there exist welfare equivalent, positive capital flow equilibria under each double taxation scheme.

Q.E.D. 
It is instructive to compare Proposition 1 with the results of Bond and Samuelson. In both papers, the two key home government's motives for setting the tax rate on the return from FDI is to appropriate the returns associated with its FDI and to counter what it perceives as excessive host-capital financing and host employment by home subsidiaries. We can understand the first motive in terms of the Ramaswami (1968)/Calvo-Wellisz (1983) (RCW) strategy of restricting exports of home capital and importing the scarce resources, in this case host capital and labor. Under the original version of this strategy, the home government seeks to leave host factor prices unchanged and simply increase the return to home capital. Although Ramaswami's strategy explicitly required mobile host labor, Calvo and Wellisz demonstrated that the home country need only be able to channel the returns from host labor to home sources. ${ }^{14}$ Multinational investment provides one such channel. Jones, Coelho, and Easton (1986) reveal that even greater gains in home national income can be achieved if home can appropriately manipulate host factor prices to create a favorable "terms-of-trade" effect. Bond and Samuelson find that this is achieved by setting $t^{e}\left(t^{\prime}\right)$ greater than $t^{*}$ with both credit and deduction rules. This is because with only home-equity capital available, the home government is always able to influence host factor prices through the effective tax rate. In our model, since host factor prices are controlled indirectly via tax rates, any attempt at implementing the RCW strategy incurs welfare costs from distorted equity levels. Furthermore, since multiple sectors in the host can lead to factor prices which are unresponsive to tax rates, the RCW strategy may result only in a welfare-reducing distortion. That is, we find that with alternative modes of finance, host factor prices do not change as the effective tax changes because capital and labor are reallocated between the subsidiary and host sectors in a way that does not affect capital-labor ratios in the host country. Since the home government has no ability to manipulate host factor prices, it will simply choose a tax rate that yields $t^{e} \# t^{(}$regardless of the relief method. Similarly, the host problem does not change across relief methods since in each it balances changes in the tax base with its share of the tax base. This yields welfare equivalent equilibria across all three relief methods even with the 
discriminatory taxation of Bond and Samuelson. Thus, this result is due to the general equilibrium properties of the economy that permit us to write host factor prices as functions of capital-labor ratios that are exogenous with respect to the effective tax. ${ }^{15}$

\subsection{Welfare Equivalence in a Generalized Model.}

Proposition 1 is easily generalized in a way that helps distinguish the economic conditions that generate the equivalence results in Janeba (1995) and in our Proposition 1 from those that generate the Bond and Samuelson result. Consider a host economy that uses many factors to produce an arbitrary number of goods using constant returns to scale technologies. Some of these factors may be supplied in the host country and some may also be supplied from the home country, possibly exclusively. We will refer to this description of the host economy as our "generalized model." Let the phrase "host factor" denote a factor of production that is endowed in a positive amount the host country. The number of host factors equals $R$ and the number of sectors located in the host that use only host factors equals $N$. In our base model, $N=2$ and $R=2$. Now consider an autarkic situation so that no home factors can flow into the host economy. If in this autarkic situation, the $R$ host factor prices are fully determined within the $N$ sectors, then allowing for home factors to flow into the host country cannot change host factor prices.

Proposition 2: In the generalized model with an arbitrary number of factors and sectors, if $N \$ R$, then there exist equilibria under all three double-tax relief methods that are welfare equivalent to $\left\{t, t^{\prime}\right\}{ }^{\prime}\left\{0, t_{\text {opt }}^{(}\right\}$.

Proof: Under constant returns to scale, when $N=R$, the $R$ host factor prices are defined by exactly $R$ equilibrium factor market conditions that depend only on host factor ratios. If $N>R$, then there are $N-R$ redundant sectors that may only operate in equilibrium in knife-edge cases. Note that the smallest number of sectors that will operate in equilibrium is $R$ and that the identity of the operating sectors will be independent of the effective tax rate or the level of imported factors. Thus, the $R$ host factor prices will still be defined by $R$ equilibrium conditions that depend only on host factor ratios. 
With constant host factor prices, if the home country chooses a tax rate such that the effective tax is other than the host tax, it will only incur a loss as it distorts capital flows. Therefore, the home country's best response is the same as that described above, i.e., it will set $t^{e}\left(t^{\prime}\right)^{\prime} t^{\prime}$. Similarly, the host problem still involves a trade off between the tax rate and the size of the tax base. Since best responses in tax rates have not changed, neither will the set of equilibria. So just as with Proposition 1, there exist equilibria under all three relief methods that are welfare equivalent.

Q.E.D.

The condition on host factors and sectors in Proposition 2 is the familiar result from the trade literature that yields factor price equalization. Note that this condition places no restrictions on the subsidiary sectors located in the host, that is those that can or must use imported factors or factors supplied outside the host. There can be many such sectors (some of which may be redundant and may not operate in equilibrium) or none (as in the baseline case above). Proposition 2 implies that perfect substitutability between home and host capital is not necessary for our results if there are sufficiently many host sectors which can absorb or release host capital. Thus, in a fairly general model of foreign direct investment conditions on the number of host sectors and factors reveal when the tax spiral of Bond and Samuelson can be avoided. ${ }^{16}$

\section{Economies Without Welfare Equivalence.}

It is natural to ask under what conditions the above equivalence result fails. In this section, we present two: specific factors and increasing borrowing costs.

\subsection{Specific factors.}

In the above model, we found that when both the host and the subsidiary use the same two factors, capital and labor, tax competition equilibria were welfare-equivalent. Instead, suppose that subsidiary production is given by $f^{s}\left(Z, L^{s}\right)$ and host production is given by $f^{(}\left(K^{(}, L^{(} \& L^{s}\right)$, i.e., host labor is used in both sectors but there are two types of capital, one specific to each sector. Now $N=1$ and $R=2$ but the subsidiary sector is only employing one host factor, which is less than $R-N+1 .{ }^{17}$ Note that 
this is equivalent to a situation in which host production uses only labor but has a decreasing returns to scale technology. Here, we have two factor market equilibrium equations:

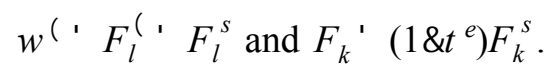

Totally differentiating, we find that

and

$$
\frac{d Z}{d t^{e}} \cdot \frac{f_{k}}{1 \& t^{e}} \cdot \frac{f_{l l}^{s} \% f_{l l}^{(}}{\left.f_{k k}\left(f_{l l}^{s} / \oint_{l l}^{(}\right) \% 1 \& t^{e}\right) f_{k l}^{s} f_{l l}^{(}}<0
$$

$$
\frac{d L^{s}}{d t^{e}} \cdot \& \frac{f_{k}}{1 \& t^{e}} \cdot \frac{f_{k l}^{s}}{\left.f_{k k}\left(f_{l l}^{s o} / \phi_{l l}^{(}\right) \% 1 \& t^{e}\right) f_{k f}^{s} f_{l l}^{(}}<0
$$

Under this alternative specification, there is no change in the host government's objective and the host's best response under the various double taxation rules remains comparable to the baseline case. The home country's best response, however, differs considerably. Using the new factor market equilibrium conditions, the home government's objective can still be written as (6) with the first order condition given by (7). However, the first order condition no longer reduces to (8) and is instead given by

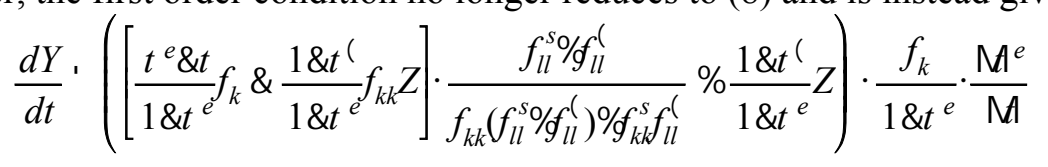

which, when $t^{e} t^{\prime}$ reduces to

$$
\frac{d Y}{d t} \cdot \frac{\left(1 \& t^{(}\right) f_{k l}^{s} f_{l l}^{(} Z}{\left.f_{k k}\left(f_{l l}^{s} \% \oint_{l l}^{(}\right) \% 1 \& t^{\prime}\right) f_{k l}^{s} f_{l l}^{(}} \cdot \frac{f_{k}}{1 \& t^{e}} \cdot \frac{\mathrm{M}^{e}}{\mathrm{M}} \% \frac{\mathrm{M}^{e}}{\mathrm{M}}
$$

Thus, so long as the home tax rate can influence the effective tax rate, as with credits or deductions, it has an incentive to raise the effective tax above the foreign tax rate (but not so high as to cut off all capital flows), i.e. $t^{(} \# t^{e}\left(t^{l}\right) \# t^{\max }$ with strict inequalities for $t^{(}<t^{\max }$. This implies that under credits, the home best response is to set $t_{c}\left(t^{(}\right)^{\prime} t^{e}\left(t^{(}\right)>t^{\prime}$, as illustrated in Figure 1. Under deductions, home's best 
response is to set $t_{d}\left(t^{(}\right)^{\prime} \frac{t^{e}\left(t^{\prime}\right) \& t^{\prime}}{1 \& t^{\prime}}$, i.e. some positive tax rate. This is illustrated in Figure 2 . Note that although we draw $t_{d}\left(t^{(}\right)$and $t_{d}^{(}(t)$ as strictly downward sloping they need not be. With these new home best responses, the equilibria under deductions and credits are those found by Bond and Samuelson, i.e. there exists a positive capital flow equilibrium under deductions (since neither country desires to cut off capital flows unless the other does) but not under credits (since home always wants $t_{c}\left(t^{(}\right)>t^{(}$while foreign always wants $\left.t_{c}^{(}(t) \$ t\right)$. These results are shown graphically in Figures 1 and 2. Thus, if specific factors are introduced without also introducing the sufficient number of additional host sectors described by Proposition 3, we return to the dire Bond and Samuelson result under credits.

\section{[FIGURES 1 AND 2 HERE]}

\subsection{Increasing Borrowing Costs.}

Alternatively we can alter the baseline model by assuming that all host financing is debt and by modeling two costs associated with borrowing host capital: the endogenous base interest rate, $r^{*}$, that reflects the marginal opportunity cost of the capital and an exogenous monitoring cost for highly leveraged loans to the subsidiary sector. We attribute this increased cost to the greater ability of a home parent relative to a host firm to shift collateral out of the host country thereby increasing collection costs for host lenders. We treat this monitoring cost as a pure resource cost that the lender, because of the competitive nature of the host capital market, passes entirely on to the borrower in the form of a higher interest rate. Denote this cost by $\varphi\left(K^{s} / Z\right)$ where $\varphi(\cdot)$ is increasing and convex. Thus, the total cost of borrowing $K^{s}$ given an equity position of $Z$ is $\left(r^{*}+\varphi\left(K^{s} / Z\right)\right) K^{s}{ }^{18}$ Both the home and host investors take $r^{*}$ and $\varphi(\cdot)$ as given. Note that in this case, even though investors treat $r^{*}$ as fixed, they perceive that the marginal cost of capital is increasing as they take on more debt, hence our "increasing borrowing costs" label.

Parent-held and parent-collateralized debt is ruled out for three reasons. First, U.S. policies set forth in the TRA 1986 and in similar rules used by other countries significantly increase the cost of 
parent-held debt by limiting associated interest deductions. Second, parent-collateralized debt creates higher enforcement costs. ${ }^{19}$ Third, the evidence in Table 1 suggests that subsidiary debt is the most prominent form of debt financing. With this in mind, we can alter the home investor's problem such that profits are:

$$
\pi^{\prime} F(K \& Z, L) \& w L \%\left(1 \& \epsilon^{e}\right)\left[F^{s}\left(Z \% K^{s}, L^{s}\right) \&\left(r^{(} \%\left(K^{s} / Z\right)\right) K^{s} \& w^{(} L^{s}\right] .
$$

Since the additional borrowing cost is a true resource cost, the host investors problem remains the same. This yields factor market equilibria:

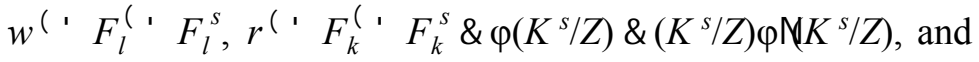

$$
\begin{aligned}
& F_{k}^{\prime}\left(1 \& t^{e}\right)\left[F_{k}^{s} \%\left(K^{s} / Z\right)^{2} \varphi \mathrm{N}\left(K^{s} / Z\right)\right]
\end{aligned}
$$

and comparative statics:

$$
\frac{d Z}{d t^{e}}, \frac{F_{k} \cdot C_{11}}{\left(1 \& t^{e}\right) \kappa}<0, \frac{d K^{s}}{d t^{e}}, \frac{\& F_{k} \cdot C_{12}}{\left(1 \& t^{e}\right) \kappa}, \text { and } \frac{d L^{s}}{d t^{e}}, \frac{F_{k} \cdot C_{13}}{\left(1 \& t^{e}\right) \kappa}
$$

where $\kappa<0, C_{11}>0$, and the signs of $C_{12}$ and $C_{13}$ depend on host and subsidiary capital labor ratios.

Exact definitions for $\kappa$ and the $C_{i j}$ are provided in Appendix A. Comparing (10) to (4) shows that $Z$ is less elastic here than in the baseline case since it is now more costly to replace decreased FDI with increased borrowing. In other words, an increase in $t^{e}$ will cause $Z$ to fall by less in the increasing borrowing costs case because the home investor will want to keep more capital abroad to gain access to less expensive borrowed funds. A similar effect is found empirically by Horst (1977), where he concludes, “The firm’s ability to substitute debt for equity in financing foreign investment will limit the substitution of domestic for foreign investment" (pg. 385). The effect on borrowed capital and labor is again ambiguous. Their comparative statics are now a function of two effects: a Rybczynski effect and a cost effect. A final difference between the constant and increasing borrowing costs cases, which is key to our equilibrium analysis, is that host and subsidiary capital-labor ratios, and thus host factor prices, are no longer independent of $t^{e}$. This is because $r^{*}$ depends not only on the capital-labor ratios in the host and subsidiary sectors, but also on the relative amounts of debt and equity. Note that it is possible to subsume 
$\varphi$ into the subsidiary production function, implying that the results here would hold for a non-constant returns to scale subsidiary production function.

Once again, the host must balance changes in its tax base with its share of the tax base. Under exemptions, this results in a tax rate $t_{\text {opt }}^{(}$, whose formulation is more complicated than that in the baseline case. Again, since the host rate does not affect the effective tax under credits when $t^{(}<t$, its best response under credits is $t_{c}^{(}(t)^{\prime} \max \left\{t_{\text {opt }}^{(}, t\right\}$, the graph of which is analogous to Figure 1. Finally, under deductions, we know that the only time for which $t_{d}^{\prime}(t)^{\prime} t^{\max }$ is when $t^{\prime} t^{\max }$, implying that here too the host best response is similar to Figure 2. Thus host best responses in the increasing borrowing costs case remain comparable to the baseline case of Section 2.

As with the specific factors example above, the same cannot be said for home. Now, using the comparative statics and (6) yields

$$
\frac{\mathrm{M}}{\mathrm{M}^{e}}{ }^{\prime} \frac{F_{k}}{\left(1 \& t^{e}\right)^{2} \kappa}\left[\left(t^{e} \& t^{(}\right) F_{k} C_{11} \%\left(1 \& t^{\prime}\right) Z\left(\kappa \& F_{k k} C_{11}\right)\right] \frac{d t^{e}}{d t} .
$$

Under credits or deductions, this implies that at $t^{e} t^{\prime}$, the home country gains from an increase in the effective tax over the host tax, yielding best responses similar to those in the specific factors case and will look comparably those in Figures 1 and 2. Thus, we once again find the Bond and Samuelson outcome in which positive equilibrium capital flows are possible under deductions but not under credits. ${ }^{20}$ Note that since this case can be reinterpreted as one in which constant returns to scale fails for the subsidiary, one can also find the Bond and Samuelson result if the constant returns assumption is violated.

In addition to pointing to a limitation of Proposition 2, this increasing cost case addresses an argument by Feldstein $(1994 a, b)$ that the ability to borrow funds in a host country may be an important factor in assessing the benefits that accrue to a home government under a credit rule. Citing Feldstein and Horioka's (1980) result that most savings tend to stay within the country of origin, he reasons that endogenous interest rate differentials due to such capital market segmentation may alter a government's incentives for taxation. If the marginal cost of borrowing is dependent on the level of equity, a home 
government may have an incentive to encourage greater outbound foreign direct equity investment in order to increase the firm's ability to borrow abroad. ${ }^{21}$ Our analysis suggests that even though the home government may not desire to distort FDI flows as it does in Bond and Samuelson, it will still choose to limit FDI to reduce what it considers to be excessive borrowing. As a result, contrary to Feldstein's predictions, we still find zero capital flows under credits.

\section{Subsidiary Leverage.}

Independent of tax competition concerns, the ability to finance operations with host capital raises issues of subsidiary leverage or domestic ownership (depending on how the host capital is acquired). It is not uncommon for host countries to insist on some minimal level of domestic investment in a multinational's local operations. Our base model has implications for the incentive of home investors to use host capital based on the relative capital intensity of the subsidiary and host sectors and on the effective tax rate.

Taking $K^{s} / Z$ as a measure of how leveraged home equity is, (4) implies that

$$
\frac{d\left(K^{s} / Z\right)}{d t^{e}}, \frac{\& F_{k}}{\left(1 \& t^{e}\right) Z F_{k k}}\left[\frac{k^{(}}{k^{(} \& k^{s}} \% K^{s / Z}\right] .
$$

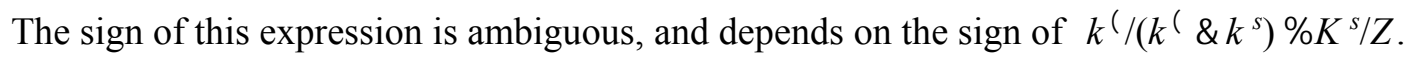

Proposition 3. Subsidiary leverage $\left(K^{s} / Z\right)$ is increasing in the effective tax rate if the host sector is more capital intensive than the subsidiary sector $\left(k^{*}>k^{s}\right)$ or if the subsidiary sector is significantly more capital intensive than the host sector $\left(k^{*}<k^{s} /\left(1+Z / K^{s}\right)\right)$. Subsidiary leverage is decreasing in the effective tax rate if the subsidiary sector is only a little more capital intensive than the host sector $\left(k^{s}>k^{*}>k^{s} /\left(1+Z / K^{s}\right)\right)$.

According to (4), increases in $t^{e}$ decreases the overall supply of capital in the host country. When the host sector is more capital intensive, the Rybczynski effect implies that output in the host sector will 
contract and output in the subsidiary sector will rise. With less home-equity investment, higher subsidiary output requires more host financing and leverage must increase. When the host sector is less capital intensive, an increase in $t^{e}$ will lower subsidiary output and host financing. Now the effect on the host-capital to home-capital ratio depends on whether $Z$ or $K^{s}$ falls faster. Because $k^{s} /\left(1 \% / K^{s}\right)^{\prime} K^{s} / L^{s}$, the rate at which $Z$ falls relative to $K^{s}$ depends on whether subsidiary production is more or less hostcapital intensive relative to host production. When subsidiary production is more host-capital intensive than host production, $K^{s}$ is relatively unresponsive to changes in taxes as the Rybczynski effect implies that relatively more host capital flows into the subsidiary. Alternatively, when subsidiary production is less host-capital intensive than host production, $K^{s}$ is more responsive to tax rate changes.

Empirical evidence summarized in Caves (1996) and Jenkins (1990) finds that subsidiaries in developing host countries are almost always much more capital intensive than the average host firm. Howenstine and Zeile (1994) find that foreign subsidiaries in the U.S. are also more capital intensive than

the average U.S. firm, but only slightly so. These results suggest that the increasing leverage case may be more descriptive of FDI into a less-developed host country while the decreasing leverage case may be descriptive of FDI into a more-developed host country. Similarly, Zebregs (1998) finds that the capitallabor ratio in developing countries is positively correlated with their income. This would suggest that even when restricting attention to developing countries, subsidiary investment is more likely to exhibit decreasing leverage in more-developed host countries.

\section{Conclusions and Extensions.}

In this paper we show that multiple sectors and multiple sources of capital for FDI alters the quantitative and qualitative features of tax competition equilibria for both credits and deductions. Most importantly, positive capital flow equilibria can now exist under credits since the existence of several financing sources can mute aggressive home taxation incentives. This yields welfare-equivalent equilibria under the three double tax rules with discriminatory taxation. We also showed that the introduction of 
sector-specific factors (holding the number of host sectors constant) or the introduction of monitoring costs, both of which are equivalent to non-constant returns to scale productions functions, can recover the strong Bond and Samuelson results. This suggests that the equivalence of double taxation rules, which requires host factor prices be independent of taxes, is sensitive to the constant returns to scale assumption. In this way, the equivalence result is similar to the sensitivity of the well-known factor price equalization theorem of international trade to scale economies. ${ }^{22}$ Thus, a small deviation from constant returns to scale is sufficient to recover the Bond and Samuelson equilibria because it creates a large marginal effect from changes in the home rate with no countervailing effect.

One possible countervailing effect could come from elastic home capital supplies. When we allow home capital to be elastically supplied, we find the same results in the baseline case as above. This is because now, in addition to the distortion on FDI flows, increasing the effective tax above the host tax carries the additional cost to home from a reduced home capital stock. When we add an endogenous home capital stock to the model in Section 1, there always exist positive capital flow $(Z>0)$ equilibria under credits. At some point the home tax rate is high enough that the home welfare costs of reduced capital supply exceed any home welfare benefits attributable to the change in FDI. This is similar to the effect of endogenous capital supply found in Bond and Samuelson (1989). For reasons related to those found in Gordon (1992), the equilibria may involve a mixed strategy by the home country.

Recall also that Janeba (1995) initially found equivalence under the three relief methods by imposing uniform taxation, i.e. the home tax rates on domestic and on subsidiary profits (prior to applying double taxation adjustments) must be equal. If we assume that both governments must tax domestic and subsidiary profits uniformly, then our equivalence result is maintained even in the alternative models of Section 3 because home national income will depend on the home rate only through its impact on the effective tax rate. Under exemptions and credits, when the home rate influences factor flows, higher home rates increase outbound FDI and lower home national income. In the baseline case, this implies that 
home's unique best response under these methods is to set a zero tax rate. In the models of Section 3, in order to implement the RCW strategy under credits or exemptions, home would use the lowest rate it can, i.e. a zero tax rate. Under deductions, the home tax is now a non-distortionary profit tax and has no effect in either case. Thus, as in Janeba (1995), we still find welfare-equivalent equilibria even in the alternative models. The primary difference between the uniform and discriminatory tax settings is that whereas the baseline model of discriminatory taxation implied an indeterminate home tax under credits, uniform taxation yields an indeterminancy under deductions.

Another extension of the increasing borrowing cost model in Section 3 would be to assume the marginal cost of borrowing schedule depends on the ratio of debt to total parent equity, $K$, instead of on the ratio of debt to subsidiary equity $Z$. In this setting, the equivalence result may or may not arise. Here, the first order condition for home at $t^{e} t^{(}$is proportional to

$$
\frac{k^{(}}{k^{s}}\left(K^{s} \%\left(1 \& t^{(}\right) Z\right) \& K^{s}
$$

which has an ambiguous sign. ${ }^{23}$ When the host sector is sufficiently capital intensive, increasing the effective tax leads to a large enough increase in borrowed capital and labor that factor prices move in the home country's favor. When the host is sufficiently labor intensive, the factor movements induced by an increase in the effective tax work to home's detriment. Consequently, depending on the parameters chosen, the equilibrium under credits can result in a Bond and Samuelson (1989) or a Janeba (1995) result. Thus, while our equivalence under discriminatory taxation can be generalized, it can fail if we do not have the requisite number of host factors and sectors, have factor costs which are not functions only of factor ratios, or have non-constant returns. 
6. Appendix A - Exact expressions for equation (10).

Let $\left(\varphi \cdot K^{s}\right)_{11} / \mathrm{M}\left(\varphi \cdot K^{s}\right) / \mathrm{MK}^{s^{2}}$. It is strictly positive. Then

$$
\begin{aligned}
& C_{11} / F_{k k}^{s} F_{k k}^{(}\left(k^{(} \& k^{s}\right)^{2} \&\left(\varphi \cdot K^{s}\right)_{11}\left[F_{k k}^{s} k^{s^{2}} \% F_{k k}^{(} k^{(2}\right]>0, \\
& C_{12} / F_{k k}^{s} F_{k k}^{(} k^{(}\left(k^{(} \& k^{s}\right) \%\left(\varphi \cdot K^{s}\right)_{11}\left(K^{s} / Z\right)\left[F_{k k}^{s} k^{s^{2}} \% F_{k k}^{(} k^{\left({ }^{2}\right.}\right], \\
& C_{13} / F_{k k}^{s} F_{k k}^{(}\left(k^{s} \& k^{(}\right) \&\left(\varphi \cdot K^{s}\right)_{11}\left[\left(1 \% K^{s} / Z\right) F_{k k}^{s} k^{s} \%\left(K^{s} / Z\right) F_{k k}^{(} k^{(}\right],
\end{aligned}
$$

and

$$
\kappa^{\prime} F_{k k} \cdot C_{11} \&\left(1 \& t^{e}\right)\left(\varphi \cdot K^{s}\right)_{11} F_{k k}^{s} F_{k k}^{(}\left(k^{(} \%\left(k^{(} \& k^{s}\right)\left(K^{s} / Z\right)\right)^{2}<0
$$




\section{Notes}

*. We thank Rick Bond and the editor and a referee of this journal for their comments.

1. Feldstein's figures are based on the stock of investment in non-bank affiliates of non-bank U.S. parents in the 1989 Benchmark Survey of U.S. Investment Abroad (U.S. Dept. of Commerce (1992)).

2. To the best of our knowledge, the only other paper that discusses the role of foreign debt in a tax competition setting is Feldstein and Hartman (1979). While our models intentionally share many similarities, the analysis and conclusions Feldstein and Hartman offer with regard to the effect of foreign debt apply only to the case in which no strategic interdependence, and hence no real tax competition, exists between the home and host countries. While Razin, Sadka, and Yuen (1998) look at the tax implications associated with debt and equity financing, in their paper it is the local firms in a capital importing country that use external debt financing.

3. In related studies, Collins and Shackelford (1992) and Froot and Hines (1995) find evidence that multinationals also substituted away from debt financing to more equity financing.

4. Gordon (1992) also considers the role of credits with non-discriminatory home taxes. He finds no pure-strategy Nash equilibrium in home and host rates but does demonstrate the existence of a Stackelberg equilibrium when the capital exporter sets its tax rate first. Since the bulk of FDI takes place between industrialized nations of similar size, it is not clear that such a leader exists.

5. $F$ and $F^{s}$ can be identical. However, without separate host and subsidiary technologies, host capital owners have no economic incentive to shift their capital between host and subsidiary investments. In Section 3, we allow $F^{s}$ and $F^{*}$ to differ but allow only home-equity financing. There, the set of tax competition equilibria under all three double tax rules is identical to that found in Bond and Samuelson (1989). For this reason, we attribute the new equilibrium behavior we derive to the introduction of hostcapital financing.

6. This is equivalent to assuming that the unit cost curves of the subsidiary and host production 
technologies cross in factor prices space, which ensures that host and subsidiary firms have different capital-labor ratios.

7. Here we depart from the standard U.S. definition of FDI, which does not distinguish between equity investment and borrowed capital, in order to identify potentially important economic and strategic differences between these two sources of investment.

8. This can be guaranteed by Inada conditions on $F$ and $F^{s}$ that are also consistent with the unit cost curve assumptions from note 7.

9. When $t^{*}>t$, the parent corporation has more foreign tax credits than it can use. Some countries that offer foreign tax credits allow excess credits to be applied against past or future tax liabilities for a limited number of years. Due to time discounting, carry-back and carry-forward options imply the firm has some, if not full, value for excess credits. If one lets $\alpha$ denote the residual value of a dollar of excess credits, then $t^{e}=\max \left\{t, \alpha t+(1-\alpha) t^{*}\right\}$ for $0 \# \alpha \# 1$. Adopting this alternative definition does not alter the qualitative properties of tax competition equilibria under credits nor does it affect the welfare comparisons of Propositions 2 or 3 . Thus, for simplicity we ignore the possibility of carry-back or carryforward provisions.

10. Because of the one-way capital flows, this model is perhaps most suggestive of tax competition between a developed capital-exporting country and a developing capital importer.

11. Domestic returns are assumed not to be taxed by either government. Since the governments seek to maximize national income, a host domestic profit tax has no welfare or strategic implications because it is purely distributional. Also, any welfare/strategic distortion created by a home domestic profit tax can be achieved by a corresponding change in $t$ alone as long as the domestic tax rate cannot be negative. We consider the case of uniform tax rates on domestic and foreign income in Section 5.

12. We focus on the role of foreign debt because of its predominance in multinational finance as indicated by Table 1 . If we instead focus on foreign equity, home investor profit would be $\pi^{\prime} F \& w L \%\left(1 \& t^{e}\right)\left(Z /\left(Z \% K^{s}\right)\right)\left[F^{s} \& w^{(} L^{s}\right]$ and host profit would be 
$\pi^{(} F^{(} \& w^{(}\left(L^{(} \& L^{s}\right) \%\left(K^{s} /\left(Z \% K^{s}\right)\right)\left[F^{s} \& w^{(} L^{s}\right]$. However, the factor market equilibria are still defined by (3) and the comparative statics are still defined by (4). Thus, the case of foreign equity is strategically equivalent to the case of foreign debt.

13. The same expression as in (6) arises with host equity.

14. Jones, Coelho, and Easton (1986) also extend the Ramaswami argument to several factors of production. Jones and Coelho (1985) determine the minimum number of internationally mobile factors sufficient to sustain the Ramaswami strategy when there are many factors and many goods. 15. In a very different model, Wilson (1987) also shows how multiple sectors can influence tax competition equilibria. In his paper, capital tax competition leads otherwise identical countries to specialize in the production of different goods with the high-tax location producing only the labor-intensive good. In our model, only the host has multiple sectors and, by virtue of the Inada conditions and the unit cost assumptions of note 7 , specialization in the host will never be complete. 16. One might conjecture that the complementary case of $R>N$ could be addressed by extending the analysis of Jones and Coelho (1985) to our model. For this case, Jones and Coelho derive a sufficient condition on the number of host sectors and the number of mobile host factors guaranteeing the existence of some change in host factor supplies that leave host factor prices unchanged. For our model, one would need to show that any change in the effective tax rate induces such an appropriate change in host factors supplied to the subsidiary sector. One appropriate set of sufficient conditions would guarantee that the set of all host factor proportion changes induced by a change in the effective tax rate lie within the cone of diversification of the $N$ host sectors. As such, this result would depend on details of home, subsidiary, and host production functions.

17. Compare this to Bond and Samuelson (1989) where $N^{\prime} \quad 0$ and $R^{\prime} 1$.

18. This function $\varphi\left(\mathrm{K}^{\mathrm{s}} / \mathrm{Z}\right) \mathrm{K}^{\mathrm{s}}$ is the same as the agency cost function used by Osterberg (1989). These agency costs arise from manager decision-making under limited liability as first addressed by Jensen and Meckling (1976). They suggest that highly indebted firms have an incentive to take on risky projects 
with low expected returns, which leads to a higher cost of borrowing for those firms. A survey of this agency approach to firm financing can be found in Barnea, Haugen, and Senbet (1985). Stevens and Lipsey (1988) find that debt-equity ratios are correlated with domestic and foreign investment by U.S. multinationals. They attribute this finding to borrowing costs which are increasing in a firm's debt-equity ratio.

19. We discuss the implications of basing the monitoring costs on the ratio of subsidiary debt to worldwide parent capital below.

20. An earlier draft of the paper considered an increasing cost of borrowing case only when the debtequity ratio exceeded an exogenous level $\gamma$. Since this amounts to a combination of the baseline and increasing cost cases presented here, it is not surprising that, depending on factor endowments and technologies, we could find either the Bond and Samuelson or the Janeba result under discriminatory taxation. These results are available upon request.

21. Feldstein points out that foreign debt may also shield the multinational firm, and thus the home country, from currency fluctuations and expropriation risks.

22. Bhagwati, Panagariya, and Srinivasan (1998) provide a detailed discussion of the factor price equalization theorem.

23. Eq. (12) seems to suggest that the no-capital flow equilibrium of Bond and Samuelson can be ruled out when $k^{*} / k^{s}<1$. This is misleading as reductions in $t$ below $t^{*}$ have no effect on $t^{e}$ under a credit rule. 


\section{References}

Altshuler, Rosanne and Jack Mintz. (1995). "U.S. interest-allocation rules: effects and policy," International Tax and Public Finance 2:7-35.

Barnea, Amir, Robert Haugen, and Lemma Senbet. (1985). Agency Problems and Financial Contracting, Prentice-Hall, Englewood-Cliffs Publishers.

Bhagwati, Jagdish, Arvind Panagariya, and T.N. Srinivasan. (1998). Lectures on International Trade, $2^{\text {nd }}$ Edition, Cambridge: The MIT Press.

Bond, Eric and Larry Samuelson. (1989). "Strategic behaviour and the rules for international taxation of capital," Economic Journal 99:1099-1111.

Calvo, Guillermo and Stanislaw Wellisz. (1983). "International factor mobility and national advantage," Journal of International Economics 14:103-114.

Caves, Richard. (1996). Multinational Enterprise and Economic Analysis, $2^{\text {nd }}$ ed., Cambridge University Press.

Collins, Julie and Douglas Shackelford. (1992). "Foreign tax credit limitations and preferred stock issuances," Journal of Accounting Research 30:103-124.

Feldstein, Martin. (1994a). "Taxes, leverage, and the national return on outbound foreign direct investment," NBER Working Paper, No. 4689.

Feldstein, Martin. (1994b). "Tax policy and international capital flows," NBER Working Paper, No. 4851. Feldstein, Martin. (1995). "The effects of outbound foreign direct investment on the domestic capital stock," in The Effects of Taxation on Multinational Corporations, Martin Feldstein, James Hines, Jr., and R. Glenn Hubbard eds., University of Chicago Press.

Feldstein, Martin and David Hartman. (1979). "The optimal taxation of foreign source investment income," Quarterly Journal of Economics 93:613-629. 
Feldstein, Martin and Charles Horioka. (1980). "Domestic saving and international capital flows," Economic Journal 90:314-29.

Froot, Kenneth and James Hines, Jr. (1995). "Interest allocation rules, financing patterns, and the operations of U.S. multinationals," in The effects of taxation on multinational corporations, Martin Feldstein, James Hines Jr., and R. Glenn Hubbard eds., University of Chicago Press.

Gordon, Roger. (1992). "Can capital income taxes survive in open economies?" The Journal of Finance 67:1159-80.

Hamada, Koichi. (1966). "Strategic aspects of taxation on foreign investment income," Quarterly Journal of Economics 80:361-75.

Hartman, David. (1985). “Tax policy and foreign direct investment," Journal of Public Economics 26:107-121.

Hines, James Jr. (1988). "Taxation and U.S. multinational investment," in Tax Policy and the Economy, Lawrence Summers ed., MIT Press.

Hines, James Jr. (1994). "Credit and deferral as international investment incentives," Journal of Public Economics 55:323-347.

Horst, Thomas. (1977). "American taxation of multinational firms," American Economic Review 67:37689.

Howenstine, Ned and William Zeile. (1994). "Characteristics of foreign-owned U.S. manufacturing establishments," Survey of Current Business 74:34-59.

Hufbauer, Gary. (1992). U.S. Taxation of International Income: Blueprint for Reform, Institute for International Economics.

Janeba, Eckhard. (1995). "Corporate income tax competition, double taxation treaties, and foreign direct investment," Journal of Public Economics 56:311-325.

Jenkins, Rhys. (1990). "Comparing foreign subsidiaries and local firms in LDCs: Theoretical issues and 
empirical evidence," Journal of Development Studies 26: 205-228.

Jensen, Michael and William Meckling. (1976). "Theory of the firm: managerial behavior, agency costs and ownership structure," Journal of Financial Economics, 3:305-360.

Jones, Ronald and Isaias Coelho. (1985). "International factor movements and the Ramaswami argument," Economica 52:359-364.

Jones, Ronald, Isaias Coelho and Stephen Easton. (1986). "The theory of international factor flows: the basic model," Journal of International Economics 20:313-327.

Leechor, Chad and Jack Mintz. (1993). "On the taxation of multinational corporate investment when the deferral method is used by the capital exporting country," Journal of Public Economics 51:75-96.

Newlon, T. Scott. (1987). "Tax policy and the multinational firm's financial policy and investment decisions," Unpublished Ph.D. dissertation, Princeton University.

Osterberg, William. (1989). “Tobin’s q, investment, and the endogenous adjustment of financial structure," Journal of Public Economics, 40: 293-318.

Ramaswami, V. (1968). "International factor movement and the national advantage," Economica 35:309310.

Razin, Assaf, Efraim Sadka, and Chi-wa Yuen. (1998). "A pecking order of capital inflows and international tax principles," Journal of Public Economics 44:45-68.

Rybczynski, Tadeus. (1955). "Factor endowments and relative commodity prices," Economica 22:336341.

Stevens, Guy and Robert Lipsey. (1988). "Interactions between domestic and foreign investment," International Finance Discussion Papers, No. 329, Board of Governors of the Federal Reserve System. U.S. Department of Commerce. (1992). 1989 Benchmark Survey of U.S. Investment Abroad, U. S. Government Printing Office: Washington D.C.. Wilson, John. (1987). "Trade, capital mobility, and tax competition," Journal of Political Economy 
95:835-856.

Wilson, G. Peter. (1993). "The role of taxes in location and sourcing decisions," in Studies in International Taxation, Alberto Giovannini, R. Glenn Hubbard, and Joel Slemrod eds., University of Chicago Press.

Zebregs, Harm. (1998). "Can the neoclassical model explain the distribution of foreign direct investment across developing countries?” International Monetary Fund Working Paper, No. WP/98/193. 
Table 1: 1989 Benchmark Survey of U.S. Investment Abroad

\begin{tabular}{c|c}
\hline \hline Equity capital from U.S. sources & $\$ 203$ billion \\
\hline Debt from U.S. sources & $\$ 47$ billion \\
\hline Equity from non-U.S. sources & $\$ 92$ billion \\
\hline Debt from non-U.S. sources & $\$ 567$ billion \\
\hline Retained earnings & $\$ 328$ billion \\
\hline
\end{tabular}


FIGURE 1: Tax credit equilibrium

FIGURE 2: Tax deduction equilibrium 


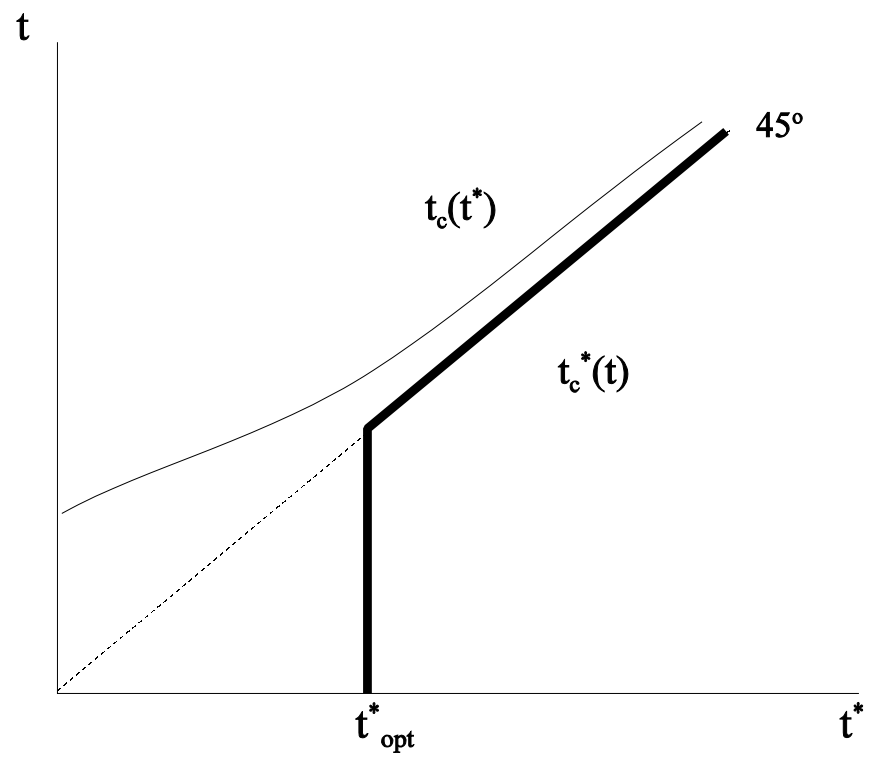




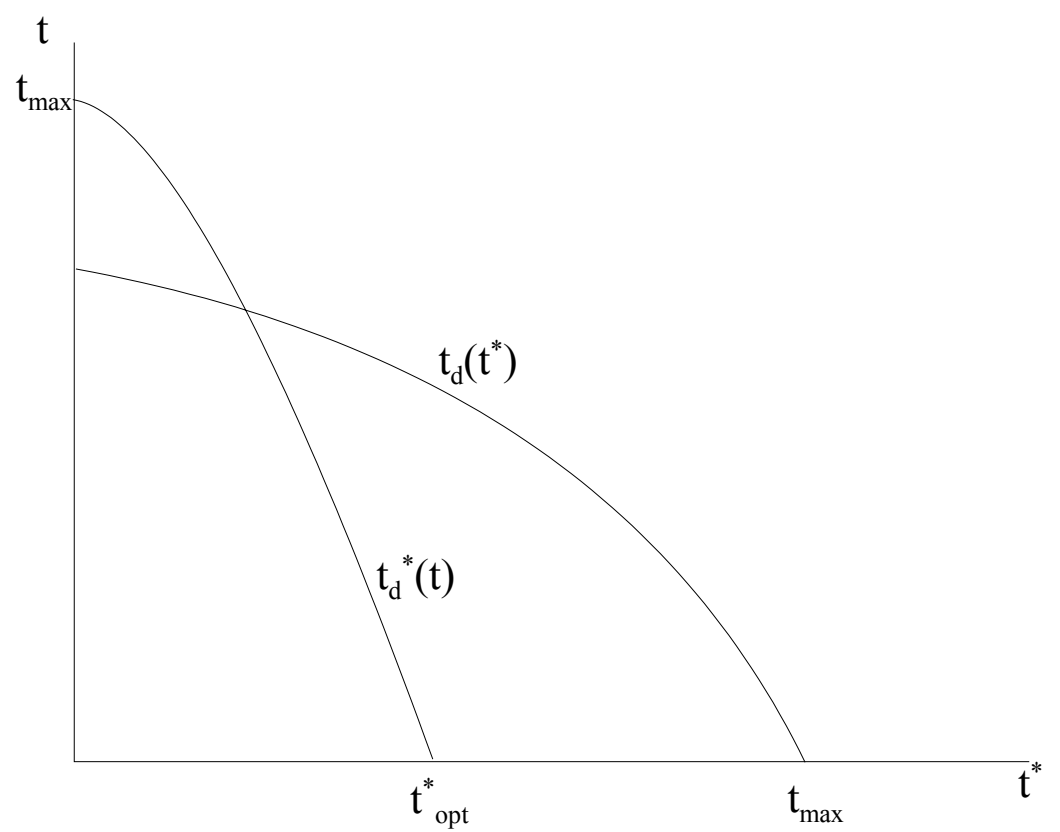

